\title{
Pengaruh Etos Kerja dan Job Insecurity terhadap Kepuasan Kerja Karyawan pada PT. Danamas Insan Kreasi Andalan (DIKA) Denpasar
}

\author{
I Kadek Putrayasa ${ }^{(1)}$ \\ I Made Astrama ${ }^{(2)}$ \\ ${ }^{(1)(2)}$ Fakultas Ekonomi, Bisnis, dan Pariwisata Universitas Hindu Indonesia \\ e-mail: kadekputra709@yahoo.co.id
}

\begin{tabular}{|l|l|l|}
\hline Diterima: 3 Desember 2020 & Direvisi: 10 Desember 2020 & Disetujui: 20 Desember 2020 \\
\hline
\end{tabular}

\begin{abstract}
To be able to bring progress to the company and result in the creation of job satisfaction an employee requires employees who have a high work ethic. A part from work ethic, the existence of job insecurity also has an impact on employee job satisfaction. The purpose of this study was to determine the effect of work ethic and job insecurity on job satisfaction. The sample used 86 respondents. The data analysis technique used the validity test, reliability, classical assumptions, multiple linear regression, coefficient of determination, $t$ and $F$. The results show that work ethic has a significant positive effect on job satisfaction, job insecurity has a significant negative effect on job satisfaction, and simultaneously work ethic and job insecurity is significant towards job satisfaction. The amount of influence of the independent variables on job satisfaction is 52.9\%. Suggestions that can be given are PT. Danamas Insan Kreasi Andalan (DIKA) Denpasar is expected to provide motivation to its employees, provide opportunities for promotion for employees and always supervise employees at work.
\end{abstract}

Keywords: work ethic, job insecurity and job satisfaction

\begin{abstract}
ABSTRAK
Untuk dapat membawa kemajuan bagi perusahaan serta berakibat pada terciptanya kepuasan kerja seorang karyawan dibutuhkan karyawan yang memiliki etos kerja yang tinggi. Selain etos kerja, adanya job insecurity (ketidakamanan kerja) juga berdampak pada kepuasan kerja karyawan. Tujuan dalam penelitian ini untuk mengetahui pengaruh etos kerja dan job insecurity terhadap kepuasan kerja. Sampel yang digunakan sebanyak 86 responden. Teknik analisis data yang digunakan adalah Uji Validitas, Reliabilitas, Asumsi Klasik, Regresi Linier Berganda, Koefisien Determinasi, t dan F. Hasil penelitian menunjukkan etos kerja berpengaruh positif signifikan terhadap kepuasan kerja, job insecurity berpengaruh negatif signifikan terhadap kepuasan kerja, dan secara simultan etos kerja dan job insecurity signifikan terhadap kepuasan kerja. Besarnya pengaruh variabel bebas terhadap kepuasan kerja adalah 52,9\%. Saran yang dapat diberikan adalah PT. Danamas Insan Kreasi Andalan (DIKA) Denpasar diharapkan memberikan motivasi kepada karyawannya, memberikan kesempatan untuk promosi bagi karyawan dan selalu mengawasi karyawan dalam bekerja.
\end{abstract}

Kata kunci: etos kerja, job insecurity dan kepuasan kerja 


\section{Pendahuluan}

Sumber daya manusia (SDM) merupakan aspek yang memegang peranan penting dalam pencapaian tujuan organisasi sehingga perusahaan tentunya akan sangat mengharapkan setiap karyawannya untuk menghasilkan kinerja yang minimal sesuai dengan target yang ditetapkan perusahaan. Untuk dapat mempertahankan karyawan yang telah menunjukkan kinerja yang baik tentu bukanlah suatu perkara mudah bagi perusahaan, karena perusahaan tentu saja harus terlebih dahulu memahami apa yang menjadi kebutuhan dan keinginan dari karyawan tersebut.

Salah satu perusahaan yang bergerak di bidang jasa pelayanan adalah PT. Danamas Insan Kreasi Andalan (DIKA). PT. DIKA menyediakan layanan pemasaran, jasa penjualan, pelayanan pelanggan, dan pengembangan sumber daya manusia untuk klien eksklusif yaitu Bank Central Asia (BCA). Fokus utama dari bisnis PT. DIKA adalah bagaimana memberikan nilai tambah ke dalam proses bisnis dari klien kepada para pelanggan atau nasabah. Untuk dapat melakukan pelayanan dengan maksimal tentunya dibutukan karyawan yang memiliki kualitas yang baik.

Kinerja karyawan sangat dipengaruhi oleh tingkat kepuasan kerja yang dimiliki. Setiap karyawan akan merasa puas terhadap pekerjaannya, apabila apa yang dikerjakan dianggap telah memenuhi harapannya. Menurut Siagian (dalam Priansa Donni, 2010:229), kepuasan kerja adalah sikap umum seseorang pegawai terhadap pekerjaannya. Setiap individu memiliki tingkat kepuasan yang berbeda-beda. Kepuasan kerja merupakan indikator penting bagi karyawan itu sendiri maupun bagi perusahaan. Peningkatan kepuasan kerja karyawan akan membawa kemajuan bagi karyawan itu sendiri maupun perusahaan.

Untuk dapat membawa kemajuan bagi perusahaan serta berakibat pada terciptanya kepuasan kerja seorang karyawan dibutuhkan karyawan yang memiliki etos kerja yang tinggi. Buchari (dalam Donni, 1994:133), etos kerja merupakan sikap terhadap kerja, pandangan terhadap kerja, kebiasaan kerja, ciri-ciri atau sifat mengenai cara bekerja yang dimiliki seseorang, golongan, atau suatu bangsa. Karyawan yang memiliki etos kerja akan memiliki kinerja yang baik serta akan merasa puas sehingga membawa dampak yang baik bagi perusahaan. Kinerja dapat ditingkatkan apabila kepuasaan pekerjaan karyawan dirasakan telah terpenuhi (Mahadi (2007)). Jadi, etos kerja perlu ada dalam diri karyawan karena diharapkan menunjang kinerja yang akan dihasilkan sehingga akan memengaruhi kepuasan kerja. Hal ini sesuai dengan penelitian yang dilakukan oleh Ardiansyah (2017) dimana etos kerja berpengaruh positif dan signifikan terhadap kepuasan kerja karyawan. Serta penelitian yang dilakukan oleh Suparman (2017) di mana etos kerja berpengaruh terhadap kepuasan kerja. 
Selain etos kerja, adanya job insecurity (ketidakamanan kerja) juga berdampak pada kepuasan kerja karyawan. Menurut Smithson \& Lewis (2000), job insecurity adalah kondisi psikologis seseorang (karyawan) yang menunjukkan rasa bingung atau merasa tidak aman dikarenakan kondisi lingkungan yang berubah-ubah (perceived impermanance). Kondisi ini muncul karena banyaknya jenis pekerjaan yang sifatnya sesaat. Job insecurity dapat muncul karena pekerjaan yang diberikan tidak memiliki durasi waktu yang permanen atau hanya bersifat sementara. Adapun penelitian yang dilakukan oleh Kurniawan \& Arsanti (2017) di mana secara signifikan job insecurity berpengaruh secara negatif terhadap kepuasan kerja. Serta penelitian yang dilakukan oleh Setiawan \& Putra (2016) di mana hasil penelitiannya menunjukkan job insecurity berpengaruh negatif signifikan terhadap kepuasan kerja karyawan. Semakin tinggi tingkat job insecurity yang dirasakan karyawan maka semakin rendah tingkat kepuasan kerja yang dirasakan karyawan.

Tujuan penelitian ini adalah untuk mengetahui pengaruh etos kerja terhadap kepuasan kerja karyawan pada PT. Danamas Insan Kreasi Andalan (DIKA) Denpasar, untuk mengetahui pengaruh job insecurity terhadap kepuasan kerja karyawan pada PT. Danamas Insan Kreasi Andalan (DIKA) Denpasar, dan untuk mengetahui pengaruh etos kerja dan job insecurity secara simultan terhadap kepuasan kerja karyawan pada PT. Danamas Insan Kreasi Andalan (DIKA) Denpasar.

\section{Telaah Literatur dan Kajian Pustaka}

\section{Kepuasan Kerja}

Menurut Byars dan Rue (2008) mengatakan bahwa, kepuasan kerja yang tinggi akan mendorong terwujudnya tujuan perusahaan secara efektif. Sebaliknya, tingkat kepuasan kerja yang rendah merupakan ancaman yang akan membawa kehancuran atau kemunduran bagi perusahaan, baik secara cepat atau perlahan. Robbins (2006) menyatakan bahwa, kepuasan kerja sebagai suatu sikap umum seorang individu terhadap pekerjaannya. Adapun menurut Siagian (2010), kepuasan kerja adalah sikap umum seseorang pegawai terhadap pekerjaannya. Pendapat selanjutnya dikemukakan oleh George dan Jones (2002:112), kepuasan kerja merupakan kumpulan feelings dan beliefs yang dimiliki orang tentang pekerjaaannya.

\section{Etos Kerja}

Anoraga (2009) mengatakan bahwa, etos kerja merupakan pandangan dan sikap suatu bangsa atau umat terhadap kerja. Apabila individu-individu dalam komunitas memandang kerja sebagi suatu hal yang luhur bagi eksistensi manusia, etos kerjanya cenderung tinggi, sedangkan Menurut Sinamo (2005), etos kerja adalah seperangkat perilaku positif yang berakar pada keyakinan fundamental yang disertai dengan komitmen total pada paradigma kerja yang intergral. 
Cherrington (Boatwright dan Slate, 2000) menyatakan, etos kerja mengarah pada sikap positif pegawai terhadap pekerjaan yang diembanya. Hal ini berarti bahwa pegawai yang menikmati pekerjaan memiliki etos kerja yang lebih besar dari pada pegawai yang tidak menikmati pekerjaanya.

\section{Job Insecurity}

Smithson dan Lewis (2000) mengartikan bahwa, job insecurity sebagai kondisi psikologis seseorang (karyawan) yang menunjukkan rasa bingung atau merasa tidak aman dikarenakan kondisi lingkungan yang berubah-ubah (perceived impermanance). Kondisi ini muncul karena banyaknya jenis pekerjaan yang sifatnya sesaat atau pekerjaan kontrak. Makin banyaknya jenis pekerjaan dengan durasi waktu yang sementara atau tidak permanen, menyebabkan semakin banyaknya karyawan yang mengalami job insecurity.

Penelitian yang dilakukan oleh Ardiansyah (2017) menunjukkan bahwa hasil uji hipotesis secara simultan terdapat pengaruh yang positif dan signifikan antara variabel gaya kepemimpinan dan etos kerja terhadap kepuasan kerja karyawan serta hasil uji hipotesis secara parsial terdapat pengaruh yang positif dan signifikan antara variabel gaya kepemimpinan dan etos kerja terhadap kepuasan kerja karyawan. Penelitian oleh Suparman (2017), menunjukkan bahwa hasil pengujian secara parsial etos kerja berpengaruh terhadap kepuasan kerja serta hasil pengujian secara parsial pembelajaran organisasi berpengaruh terhadap kepuasan kerja, serta hasil pengujian secara simultan etos kerja dan pembelajaran organisasi berpengaruh terhadap kepuasan kerja. Penelitian oleh Setiawan \& Putra (2016). Hasil pengujian hipotesis variabel job insecurity terhadap turnover intention menunjukkan adanya pengaruh positif dan signifikan., serta hasil pengujian hipotesis variabel job insecurity terhadap kepuasan kerja menunjukkan adanya pengaruh negatif signifikan. Penelitian oleh Kurniawan \& Arsanti (2017), menunjukkan job insecurity berpengaruh secara negatif terhadap kepuasan kerja secara signifikan, jenis kelamin dapat memoderasi pengaruh job insecurity terhadap kepuasan kerja, serta usia dapat memoderasi pengaruh job insecurity terhadap kepuasan kerja.

H1. Diduga etos kerja berpengaruh positif dan signifikan terhadap kepuasan kerja karyawan pada PT. Danamas Insan Kreasi Andalan (DIKA) Denpasar.

H2. Diduga job insecurity berpengaruh negatif dan signifikan terhadap kepuasan kerja karyawan pada PT. Danamas Insan Kreasi Andalan (DIKA) Denpasar.

H3. Diduga etos kerja dan job insecurity berpengaruh positif dan signifikan terhadap kepuasan kerja karyawan pada PT. Danamas Insan Kreasi Andalan (DIKA) Denpasar. 


\section{Metode Penelitian}

Metode dalam penelitian ini digunakan untuk mengetahui hubungan antara variabel etos kerja, dan job insecurity terhadap kepuasan kerja karyawan pada PT. Danamas Insan Kreasi Andalan (DIKA) Denpasar. Penelitian ini dilakukan pada PT. Danamas Insan Kreasi Andalan (DIKA) Denpasar yang beralamat di Jalan PB Sudirman, Ruko Sudirman Blok C No. 33, Dauh Puri Kelod, Kecamatan Denpasar Barat, Bali. Adapun yang menjadi obyek penelitian ini adalah etos kerja dan job insecurity terhadap kepuasan kerja karyawan PT. DIKA Denpasar. Variabel dalam penelitian adalah kepuasan kerja karyawan (Y), etos kerja (X1), dan job insecurity (X2). Model konseptual penelitian ini dapat dilihat pada Gambar 1.

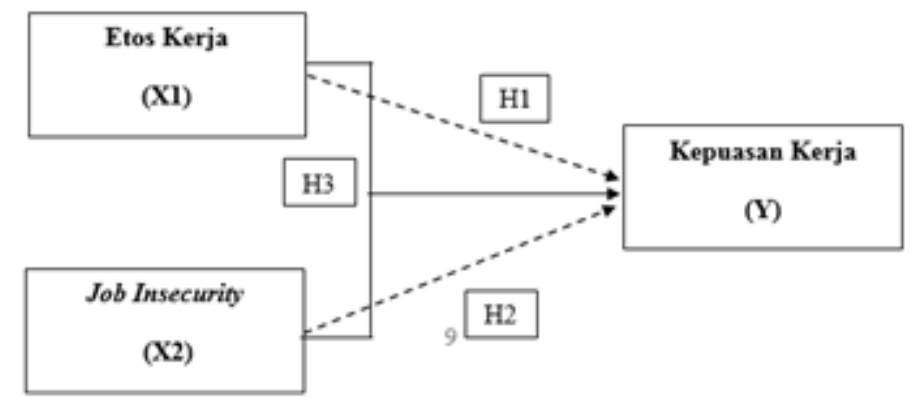

Gambar 1. Model Konseptual Penelitian

Populasi dalam penelitian ini adalah seluruh karyawan PT. DIKA yang berjumlah 86 orang. Metode pengambilan sampel yang digunakan dalam penelitian ini adalah teknik sampling jenuh atau sensus. Teknik Sampling Jenuh atau sensus adalah teknik penentuan sampel bila semua anggota populasi digunakan sebagai sampel sehingga dalam penelitian ini mengambil sampel seluruh karyawan di PT. DIKA Denpasar.

Penelitian ini menggunakan kuesioner yang akan diberikan langsung kepada responden yang berada di lokasi penelitian, dan nantinya akan diukur dengan skala likert. Nilai dari skala likert yaitu, skor 1 jika jawaban responden sangat tidak setuju, 2 jika jawaban responden tidak setuju, 3 jika jawaban responden ragu-ragu, 4 jika jawaban responden setuju, dan 5 jika jawaban responden sangat setuju.

Pengujian instrumen yaitu dengan melakukan pengujian validitas yaitu alat ukur untuk mengetahui data yang diteliti apakah valid atau tidak valid dalam suatu instrumen dan pengujian reliabilitas untuk mengetahui suatu instrumen cukup dapat dipercaya untuk digunakan sebagai alat pengumpul data karena instrumen tersebut sudah dikatakan baik. Uji asumsi klasik, yang terdiri atas uji normalitas, uji multikolinearitas, dan uji heteroskedastisitas. Teknik analisis regresi linear berganda dilakukan untuk mengetahui bentuk hubungan menyeluruh tentang hubungan antara variabel bebas yang terdiri dari etos kerja dan job insecurity terhadap kepuasan kerja karyawan. 


\section{Hasil Penelitian dan Pembahasan}

Berdasarkan hasil uji instrumen dengan penyebaran kuesioner pada 86 orang responden maka seperti pada Tabel 1 dapat dilihat seluruh indikator variabel pada penelitian ini dinyatakan valid karena memiliki nilai koefisien korelasi lebih dari rtabel 0,212 dan sig lebih kecil dari 0,05. Berdasarkan hasil uji reliabilitas instrumen dapat dilihat instrumen-instrumen variabel pada penelitian ini dikatakan reliabel karena masing-masing variabel memiliki nilai alpha lebih besar dari 0,60 dan seluruh instrument terdapat dapat digunakan dalam penelitian ini.

\section{Tabel 1. Hasil Uji Validitas}

\begin{tabular}{|c|c|c|c|c|}
\hline No & Variabel & Item Pertanyaan & Koefisien Korelasi & Keterangan \\
\hline \multirow{13}{*}{1} & \multirow{13}{*}{ Etos Kerja (X1) } & $\mathrm{X} 1.1$ & 0,906 & Valid \\
\hline & & $\mathrm{X} 1.2$ & 0,943 & Valid \\
\hline & & $\mathrm{X} 1.3$ & 0,934 & Valid \\
\hline & & $\mathrm{X} 1.4$ & 0,935 & Valid \\
\hline & & $\mathrm{X} 1.5$ & 0,897 & Valid \\
\hline & & X1.6 & 0,936 & Valid \\
\hline & & $\mathrm{X} 1.7$ & 0,875 & Valid \\
\hline & & $\mathrm{X} 1.8$ & 0,939 & Valid \\
\hline & & $\mathrm{X} 1.9$ & 0,880 & Valid \\
\hline & & $\mathrm{X} 1.10$ & 0,837 & Valid \\
\hline & & $\mathrm{X} 1.11$ & 0,827 & Valid \\
\hline & & $\mathrm{X} 1.12$ & 0,942 & Valid \\
\hline & & $\mathrm{X} 2.1$ & 0,905 & Valid \\
\hline \multirow{5}{*}{2} & \multirow{4}{*}{ Job Insecurity (X2) } & $\mathrm{X} 2.2$ & 0,883 & Valid \\
\hline & & $\mathrm{X} 2.3$ & 0,874 & Valid \\
\hline & & $\mathrm{X} 2.4$ & 0,900 & Valid \\
\hline & & $\mathrm{X} 2.5$ & 0,910 & Valid \\
\hline & \multirow{11}{*}{ Kepuasan Kerja (Y) } & $\mathrm{X} 2.6$ & 0,923 & Valid \\
\hline \multirow{10}{*}{3} & & Y.1 & 0,906 & Valid \\
\hline & & Y.2 & 0,896 & Valid \\
\hline & & Y.3 & 0,857 & Valid \\
\hline & & Y.4 & 0,911 & Valid \\
\hline & & Y.5 & 0,897 & Valid \\
\hline & & Y.6 & 0,875 & Valid \\
\hline & & Y.7 & 0,882 & Valid \\
\hline & & Y.8 & 0,927 & Valid \\
\hline & & Y.9 & 0,859 & Valid \\
\hline & & Y.10 & 0,926 & Valid \\
\hline
\end{tabular}

Sumber: data diolah, 2020

\section{Tabel 2. Hasil Uji Reliabilitas}

\begin{tabular}{llcc}
\hline No & \multicolumn{1}{c}{ Variabel } & Cronbach's Alpha & Keterangan \\
\hline 1 & Etos Kerja (X1) & 0,980 & Reliabel \\
2 & Job Insecurity (X2) & 0,953 & Reliabel \\
3 & Kepuasan Kerja (Y) & 0,972 & Reliabel \\
\hline
\end{tabular}

Sumber: data diolah, 2020

Pada Tabel 3 dapat dinyatakan bahwa responden di dominasi oleh laki-laki yaitu sebanyak 60 orang dengan persentase $69,8 \%$, sedangkan perempuan sebanyak 26 orang atau 30,2\%. Hal ini dapat dilihat mayoritas responden adalah laki-laki. Responden terbanyak berumur 21-30 tahun 
sebanyak 60 orang atau 69,8\% dan paling sedikit pada responden dengan umur 41-50 tahun sebanyak 5 orang dengan persentase 5,8\%. Hal ini dapat dilihat mayoritas responden berusia 2030 tahun.

\section{Tabel 3. Karakteristik Responden}

\begin{tabular}{cc}
\hline Jenis Kelamin & Jumlah \\
Laki-Laki & 60 \\
Perempuan & 26 \\
Total & $\mathbf{8 6}$ \\
\hline Usia & \\
$20-30$ & 60 \\
$31-40$ & 21 \\
$41-50$ & 5 \\
Total & $\mathbf{8 6}$ \\
\hline Pendidikan & \\
SMA & 48 \\
Diploma & 13 \\
S1 & 25 \\
Total & $\mathbf{8 6}$ \\
\hline
\end{tabular}

Sumber: data diolah, 2020

Berdasarkan Tabel 4 diketahui persepsi responden mengenai variabel etos kerja pada PT. Danamas Insan Kreasi Andalan (DIKA) Denpasar adalah baik dengan nilai rata-rata sebesar 3,63. Hal ini berarti karyawan PT. Danamas Insan Kreasi Andalan (DIKA) Denpasar memiliki etos kerja yang tinggi.. Berdasarkan Tabel 5 diketahui persepsi responden mengenai variabel job insecurity pada PT. Danamas Insan Kreasi Andalan (DIKA) Denpasar adalah cukup tinggi dengan nilai ratarata sebesar 2,66. Hal ini berarti karyawan PT. Danamas Insan Kreasi Andalan (DIKA) Denpasar merasakan job insecurity yang cukup tinggi. Berdasarkan Tabel 6 diketahui persepsi responden mengenai variabel kepuasan kerja pada PT. Danamas Insan Kreasi Andalan (DIKA) Denpasar adalah baik dengan nilai rata-rata sebesar 3,56. Hal ini berarti karyawan puas bekerja di PT. Danamas Insan Kreasi Andalan (DIKA) Denpasar.

Berdasarkan hasil dari Tabel 7 besarnya nilai Asymp. Sig. (2-tailed) adalah sebesar 0,690 yaitu lebih besar dari 0,05 yang berarti bahwa data terdistribusi secara normal, sehingga dapat disimpulkan bahwa model memenuhi asumsi normalitas. Tabel 8 menunjukkan bahwa seluruh variabel bebas memiliki nilai tolerance $>0,10$, begitu juga dengan hasil perhitungan nilai VIF, seluruh variabel memiliki nilai VIF $<10$. Hal ini berarti bahwa pada model regresi yang dibuat tidak terdapat gejala multikolinearitas. Tabel 9 menunjukkan bahwa masing-masing model memiliki nilai signifikansi lebih besar dari 0,05. Berarti di dalam model regresi ini tidak terjadi kesamaan varian dari residual satu pengamatan ke pengamatan lainnya atau tidak terjadi heteroskedastisitas. 


\section{Tabel 4. Jawaban Responden Mengenai Etos Kerja}

\begin{tabular}{|c|c|c|c|c|c|c|c|c|c|}
\hline \multirow[t]{2}{*}{ No. } & \multirow[t]{2}{*}{ Pernyataan } & \multicolumn{5}{|c|}{ Jawaban Responden } & \multirow{2}{*}{$\begin{array}{l}\text { Jumlah } \\
\text { Skor }\end{array}$} & \multirow{2}{*}{$\begin{array}{l}\text { Rata- } \\
\text { rata } \\
\text { Skor }\end{array}$} & \multirow[t]{2}{*}{ Kriteria } \\
\hline & & 1 & 2 & 3 & 4 & 5 & & & \\
\hline 1 & $\begin{array}{l}\text { Saya terdorong untuk memiliki kesungguhan dalam } \\
\text { memenuhi sasaran atau target yang dibebankan } \\
\text { perusahaan }\end{array}$ & 0 & 11 & 28 & 32 & 15 & 309 & 3,59 & Baik \\
\hline 2 & $\begin{array}{l}\text { Saya selalu berusaha bekerja lebih keras dalam } \\
\text { melakukan pekerjaan agar mendapatkan hasil yang } \\
\text { memuaskan }\end{array}$ & 0 & 11 & 27 & 27 & 21 & 316 & 3,67 & Baik \\
\hline 3 & $\begin{array}{l}\text { Saya selalu patuh dan taat terhadap peraturan yang } \\
\text { berlaku di perusahaan }\end{array}$ & 0 & 5 & 34 & 22 & 25 & 325 & 3,78 & Baik \\
\hline 4 & Saya selalu menghargai waktu dalam bekerja & 0 & 16 & 22 & 31 & 17 & 307 & 3,57 & Baik \\
\hline 5 & $\begin{array}{l}\text { Saya bersikap terbuka mengenai tugas yang diberikan } \\
\text { oleh perusahaan }\end{array}$ & 0 & 4 & 32 & 22 & 28 & 332 & 3,86 & Baik \\
\hline 6 & $\begin{array}{l}\text { Saya selalu bersungguh-sungguh dalam melakukan } \\
\text { pekerjaan }\end{array}$ & 0 & 15 & 24 & 30 & 17 & 307 & 3,57 & Baik \\
\hline 7 & $\begin{array}{l}\text { Saya selalu mempertanggung jawabkan tugas yang telah } \\
\text { diberikan perusahaan }\end{array}$ & 0 & 9 & 33 & 25 & 19 & 312 & 3,63 & Baik \\
\hline 8 & Saya selalu menyelesaikan pekerjaan dengan tepat waktu & 0 & 15 & 24 & 29 & 18 & 308 & 3,58 & Baik \\
\hline 9 & $\begin{array}{l}\text { Saya memiliki kebiasaan untuk selalu meningkatkan apa } \\
\text { yang sudah saya capai di perusahaan }\end{array}$ & 0 & 8 & 34 & 24 & 20 & 314 & 3,65 & Baik \\
\hline 10 & Saya selalu datang lebih awal dari jam kerja perusahaan & 0 & 25 & 27 & 25 & 9 & 276 & 3,21 & Cukup \\
\hline 11 & $\begin{array}{l}\text { Saya gigih dan tekun walapun memiliki kesulitan dalam } \\
\text { bekerja }\end{array}$ & 0 & 23 & 29 & 29 & 5 & 274 & 3,19 & Cukup \\
\hline \multirow[t]{2}{*}{12} & $\begin{array}{l}\text { Saya tetap ingin bekerja pada saat kesehatan saya } \\
\text { Menurun }\end{array}$ & 0 & 14 & 24 & 26 & 22 & 314 & 3,65 & Baik \\
\hline & $\begin{array}{l}\text { Jumlah } \\
\text { Rata-rata }\end{array}$ & & & & & & $\begin{array}{l}3694 \\
308\end{array}$ & $\begin{array}{l}42,95 \\
3,63\end{array}$ & Baik \\
\hline
\end{tabular}

Sumber: data diolah, 2020

\section{Tabel 5. Jawaban Responden Mengenai Job Insecurity}

\begin{tabular}{|c|c|c|c|c|c|c|c|c|c|}
\hline \multirow{2}{*}{ No. } & \multirow{2}{*}{ Pernyataan } & \multicolumn{5}{|c|}{ Jawaban Responden } & \multirow{2}{*}{$\begin{array}{l}\text { Jumlah } \\
\text { Skor }\end{array}$} & \multirow{2}{*}{$\begin{array}{c}\text { Rata- } \\
\text { rata } \\
\text { Skor }\end{array}$} & \multirow{2}{*}{ Kriteria } \\
\hline & & 1 & 2 & 3 & 4 & 5 & & & \\
\hline 1 & $\begin{array}{l}\text { Saya menyadari pekerjaan pada perusahaan ini sangat } \\
\text { tidak berharga bagi kelangsungan hidup saya }\end{array}$ & 15 & 31 & 23 & 15 & 2 & 216 & 2,51 & Rendah \\
\hline 2 & $\begin{array}{l}\text { Saya tidak mengerjakan semua pekerjaan yang diberikan } \\
\text { oleh perusahaan }\end{array}$ & 16 & 31 & 25 & 12 & 2 & 211 & 2,45 & Rendah \\
\hline 3 & $\begin{array}{l}\text { Saya merasa terancam karena status pekerjaan secara } \\
\text { kontrak dan dapat diberhentikan kapan saja oleh } \\
\text { perusahaan }\end{array}$ & 6 & 25 & 26 & 28 & 1 & 251 & 2,92 & Cukup \\
\hline 4 & $\begin{array}{l}\text { Saya merasa tidak ada jenjang karir sehingga tidak bisa } \\
\text { mendapatkan posisi yang lebih tinggi di perusahaan }\end{array}$ & 13 & 31 & 23 & 18 & 1 & 221 & 2,57 & Rendah \\
\hline 5 & $\begin{array}{l}\text { Saya merasa ketakutan jika pada saat kontrak berakhir } \\
\text { kontrak saya tidak diperpanjang lagi oleh perusahaan }\end{array}$ & 8 & 25 & 27 & 25 & 1 & 244 & 2,84 & Cukup \\
\hline \multirow[t]{3}{*}{6} & $\begin{array}{l}\text { Saya tidak harus mengikuti segala aturan yang ada di } \\
\text { perusahaan }\end{array}$ & 19 & 22 & 26 & 19 & 0 & 217 & 2,52 & Rendah \\
\hline & Jumlah & & & & & & 1360 & 15,81 & \\
\hline & Rata-rata & & & & & & 227 & 2,66 & Cukup \\
\hline
\end{tabular}

Sumber: data diolah, 2020 


\section{Tabel 6. Jawaban Responden Mengenai Kepuasan Karyawan}

\begin{tabular}{|c|c|c|c|c|c|c|c|c|c|}
\hline \multirow{2}{*}{ No. } & \multirow{2}{*}{ Pernyataan } & \multicolumn{5}{|c|}{ Jawaban Responden } & \multirow{2}{*}{$\begin{array}{l}\text { Jumlah } \\
\text { Skor }\end{array}$} & \multirow{2}{*}{$\begin{array}{l}\text { Rata- } \\
\text { rata } \\
\text { skor }\end{array}$} & \multirow{2}{*}{ Kriteria } \\
\hline & & 1 & 2 & 3 & 4 & 5 & & & \\
\hline 1 & $\begin{array}{l}\text { Saya mematuhi setiap kebijakan dan aturan yang } \\
\text { ditetapkan perusahaan }\end{array}$ & 0 & 13 & 24 & 26 & 23 & 317 & 3,69 & Baik \\
\hline 2 & Saya tidak pernah datang tepat waktu & 0 & 11 & 24 & 30 & 21 & 319 & 3,71 & Baik \\
\hline 3 & $\begin{array}{l}\text { Jumlah gaji yang saya terima saat ini tidak sesuai } \\
\text { dengan beban kerja yang saya jalani }\end{array}$ & 0 & 21 & 25 & 34 & 6 & 283 & 3,29 & Cukup \\
\hline 4 & $\begin{array}{l}\text { Saya kurang nyaman bekerja di sini karena tidak } \\
\text { adanya peluang untuk maju atau mengembangkan } \\
\text { karier }\end{array}$ & 0 & 16 & 18 & 33 & 19 & 313 & 3,64 & Baik \\
\hline 5 & $\begin{array}{l}\text { Sistem promosi yang ditetapkan perusahaan sesuai } \\
\text { dengan kinerja yang dilakukan }\end{array}$ & 0 & 11 & 22 & 31 & 22 & 322 & 3,74 & Baik \\
\hline 6 & $\begin{array}{l}\text { Saya senantiasa mengerjakan pekerjaan dengan } \\
\text { mementingkan kualitas dari hasil pekerjaan. }\end{array}$ & 0 & 23 & 24 & 32 & 7 & 281 & 3,27 & Cukup \\
\hline 7 & Saya memiliki rekan kerja yang kooperatif & 0 & 7 & 24 & 32 & 23 & 329 & 3,83 & Baik \\
\hline 8 & $\begin{array}{l}\text { Rekan kerja saya selalu memberi nasehat, dukungan } \\
\text { dan membantu saya apabila menghadapi kesulitan } \\
\text { dalam pekerjaan. }\end{array}$ & 0 & 15 & 22 & 24 & 25 & 317 & 3,69 & Baik \\
\hline 9 & $\begin{array}{l}\text { Fasilitas yang ada di kantor memadai untuk } \\
\text { kelangsungan pekerjaan saya. }\end{array}$ & 0 & 7 & 26 & 34 & 19 & 323 & 3,76 & Baik \\
\hline \multirow[t]{3}{*}{10} & $\begin{array}{l}\text { Saya dapat menggunakan perangkat kerja yang ada } \\
\text { dengan optimal. }\end{array}$ & 0 & 16 & 22 & 25 & 23 & 313 & 3,64 & Baik \\
\hline & Jumlah & & & & & & 3117 & 36,24 & \\
\hline & Rata-rata & & & & & & 312 & 3,56 & Baik \\
\hline
\end{tabular}

Sumber: data diolah, 2020

\section{Tabel 7. Hasil Uji Normalitas}

One-Sample Kolmogorov-Smirnov Test

Unstandardized Residual

\begin{tabular}{llr}
\hline N & & 86 \\
Normal Parameters & Mean & 0 E- \\
& Std. Deviation & 6.06022542 \\
& Absolute & .077 \\
Most Extreme Differences & Positive & .050 \\
& Negative & -.077 \\
Kolmogorov-Smirnov Z & & .712 \\
Asymp. Sig. (2-tailed) & & .690 \\
\hline
\end{tabular}

Sumber : data diolah, 2020

Tabel 8. Hasil Uji Multikolinearitas

\begin{tabular}{|c|c|c|c|c|c|c|c|}
\hline \multicolumn{8}{|c|}{ Coefficients $^{a}$} \\
\hline \multirow[t]{2}{*}{ Model } & \multicolumn{2}{|c|}{$\begin{array}{c}\text { Unstandardized } \\
\text { Coefficients }\end{array}$} & \multirow{2}{*}{$\begin{array}{c}\begin{array}{c}\text { Standardized } \\
\text { Coefficients }\end{array} \\
\text { Beta } \\
\end{array}$} & \multirow[t]{2}{*}{$\mathbf{T}$} & \multirow[t]{2}{*}{ Sig. } & \multicolumn{2}{|c|}{$\begin{array}{c}\text { Collinearity } \\
\text { Statistics }\end{array}$} \\
\hline & B & Std. Error & & & & Tolerance & VIF \\
\hline (Constant) & 34.667 & 4.680 & & 7.407 & .000 & & \\
\hline Etos Kerja & .312 & .073 & .372 & 4.278 & .000 & .753 & 1.328 \\
\hline Job Insecurity & -.747 & .139 & -.467 & -5.375 & .000 & .753 & 1.328 \\
\hline
\end{tabular}

Sumber: data diolah, 2020 
Tabel 9. Hasil Uji Heteroskedastisitas

\begin{tabular}{|c|c|c|c|c|c|}
\hline \multirow[t]{2}{*}{ Model } & \multicolumn{2}{|c|}{ Unstandardized Coefficients } & \multirow{2}{*}{$\begin{array}{c}\begin{array}{c}\text { Standardized } \\
\text { Coefficients }\end{array} \\
\text { Beta }\end{array}$} & \multirow[t]{2}{*}{$\mathbf{T}$} & \multirow[t]{2}{*}{ Sig. } \\
\hline & B & Std. Error & & & \\
\hline (Constant) & 7.111 & 2.764 & & 2.573 & .012 \\
\hline Etos Kerja & -.051 & .043 & -.147 & -1.178 & .242 \\
\hline Job Insecurity & -.006 & .082 & -010 & -.077 & .939 \\
\hline
\end{tabular}

a. Dependent Variable: RES_2

Sumber: data diolah, 2020

Untuk pengujian data yang digunakan dalam penelitian ini adalah teknik analisis regresi linear berganda. Perhitungan koefisien regresi linear berganda ini dilaksanakan dengan menggunakan analisis regresi dalam hasil analisis regresi berganda yang dilakukan dengan menggunakan program IBM SPSS Statistics 20.0.

Tabel 10. Hasil Analisis Regresi Linear Berganda

\begin{tabular}{|c|c|c|c|c|c|}
\hline \multirow[t]{2}{*}{ Model } & \multicolumn{2}{|c|}{ Unstandardized Coefficients } & \multirow{2}{*}{$\begin{array}{c}\begin{array}{c}\text { Standardized } \\
\text { Coefficients }\end{array} \\
\text { Beta } \\
\end{array}$} & \multirow[t]{2}{*}{$\mathbf{T}$} & \multirow[t]{2}{*}{ Sig. } \\
\hline & B & Std. Error & & & \\
\hline (Constant) & 34.667 & 4.680 & & 7.407 & .000 \\
\hline $\begin{array}{l}\text { Etos Kerja } \\
\text { Job Insecurity }\end{array}$ & $\begin{array}{r}.312 \\
-.747\end{array}$ & $\begin{array}{l}.073 \\
.139\end{array}$ & $\begin{array}{r}.372 \\
-.467\end{array}$ & $\begin{array}{r}4.278 \\
-5.375\end{array}$ & $\begin{array}{l}.000 \\
.000\end{array}$ \\
\hline
\end{tabular}

Sumber: Data diolah, 2020

Berdasarkan Tabel 10 dapat diketahui persamaan regresinya menjadi $Y=a+\beta 1 X 1+\beta 2 X 2$. Dari persamaan di atas maka dapat dibuat persamaan regresi penelitian ini adalah $\mathrm{Y}=34,667+0,312 \mathrm{X} 1$ - 0,747X2. Interpretasi dari koefisien regresi yaitu, $\alpha=34,667$, secara statistik menunjukan bahwa nilai constant sebesar 34,667 yang artinya apabila variabel etos kerja (X1) dan job insecurity (X2) tidak mengalami perubahan maka kepuasan kerja akan sebesar konstan 34,667. $\beta 1=0,312$ secara statistik menunjukkan ada pengaruh positif antara variabel etos kerja (X1) terhadap kepuasan kerja (Y) sebesar 0,312 yang artinya setiap terjadi kenaikan (adanya) etos kerja sebesar satu satuan maka akan menyebabkan meningkatnya kepuasan kerja sebesar 0,312 satuan dengan syarat variabel lain diasumsikan sama tidak mengalami perubahan. $\beta 2=-0,747$ secara statistik menunjukkan ada pengaruh negatif antara variabel job insecurity (X2) terhadap kepuasan kerja (Y) sebesar -0,747 yang artinya setiap terjadi kenaikan (adanya) job insecurity sebesar satu satuan maka akan menyebabkan menurunkan kepuasan kerja sebesar $-0,747$ satuan dengan syarat variabel lain diasumsikan sama tidak mengalami perubahan.

Berdasarkan Tabel 11, koefisien determinasi yang ditunjukkan dari nilai R Square sebesar 0,529. hal ini berarti 52,9\% variasi variabel kepuasan kerja dapat dijelaskan oleh variasi dari kedua 
variabel independen etos kerja (X1) dan job insecurity (X2). Sedangkan sisanya $(100 \%-52,9 \%)=$ $47,1 \%$ ) dijelaskan oleh sebab-sebab lain di luar model penelitian.

\section{Tabel 11. Hasil Uji Analisis Koefisien Determinasi $\left(\mathbf{R}^{2}\right)$}

Model Summary

\begin{tabular}{ccccc}
\hline Model & $\mathbf{R}$ & R Square & Adjusted R Square & Std. Error of the Estimate \\
\hline 1 & $.727^{\mathrm{a}}$ & .529 & .517 & 6.133 \\
\hline
\end{tabular}

Sumber: Data diolah, 2020

1. Pengaruh Etos Kerja Terhadap Kepuasan Kerja Pada PT. Danamas Insan Kreasi Andalan (DIKA) Denpasar

Dari hasil penelitian diketahui adanya pengaruh positif etos kerja terhadap kepuasan kerja. Hal ini dibuktikan dengan nilai t-hitung $=4,278$ dibandingkan dengan nilai t-tabel $=1,988$, maka ternyata nilai thitung lebih besar dari nilai t-tabel, dan t-hitung berada pada daerah penolakan $\mathrm{H} 0$. Dengan demikian H0 ditolak dan H1 diterima. Dengan demikian hipotesis yang menyatakan bahwa etos kerja (X1) berpengaruh positif dan signifikan secara parsial terhadap kepuasan kerja pada PT. Danamas Insan Kreasi Andalan (DIKA) Denpasar diterima. Hasil penelitian ini mendukung penelitian sebelumnya yang dilakukan oleh Andika Ardiansyah (2017) yang.menyatakan bahwa etos kerja berpengaruh positif terhadap kepuasan kerja.

2. Pengaruh Job Insecuriy Terhadap Kepuasan Kerja Pada PT. Danamas Insan Kreasi Andalan (DIKA) Denpasar

Dari hasil penelitian diketahui adanya pengaruh negatif job insecurity terhadap kepuasan kerja. Hal ini dibuktikan dengan nilai t-hitung = -5,375 dibandingkan dengan nilai t-tabel = -1,988, maka ternyata nilai t-hitung lebih besar dari nilai t-tabel, dan t-hitung berada pada daerah penolakan H0. Dengan demikian hipotesis yang menyatakan bahwa job insecurity (X2) berpengaruh negatif dan signifikan secara parsial terhadap kepuasan kerja pada PT. Danamas Insan Kreasi Andalan (DIKA) Denpasar diterima. Hasil penelitian ini mendukung penelitian sebelumnya yang dilakukan oleh Kurniawan \& Arsanti (2017) yang menyatakan bahwa job insecurity berpengaruh negatif terhadap kepuasan kerja.

Tabel 12. Hasil Uji Signifikan Simultan (Uji F-Test)

ANOVA ${ }^{a}$

\begin{tabular}{lrrrrr}
\hline \multicolumn{1}{c}{ Model } & Sum of Squares & Df & Mean Square & F & Sig. \\
\hline Regression & 3500.134 & 2 & 1750.067 & 46.530 & $.000^{\mathrm{b}}$ \\
Residual & 3121.738 & 83 & 37.611 & & \\
Total & 6621.872 & 85 & & & \\
\hline
\end{tabular}

a. Dependent Variable: Kepuasan Kerja

b. Predictors: (Constant), Job Insecurity, Etos Kerja

Sumber: data diolah, 2020 
Dari hasil penelitian diketahui adanya pengaruh secara simultan variabel etos kerja dan job insecurity terhadap kepuasan kerja. Hal ini dibuktikan dengan nilai F-hitung $=46,530$ dibandingkan dengan nilai F-tabel = 3,11, maka ternyata nilai F-hitung lebih besar dari nilai Ftabel, dan t-hitung berada pada daerah penolakan H0. Dengan demikian H0 ditolak dan H3 diterima. Ini berarti bahwa secara statistik untuk uji satu sisi pada taraf kepercayaan $(\alpha)=5 \%$, secara simultan etos kerja (X1) dan job insecurity (X2) berpengaruh signifikan terhadap kepuasan $\operatorname{kerja}(\mathrm{Y})$.

\section{Simpulan}

Berdasarkan data yang diperoleh dari hasil analisis dapat ditarik kesimpulan, bahwa etos kerja berpengaruh positif dan signifikan secara parsial terhadap kepuasan kerja pada PT. DIKA, job insecurity berpengaruh negatif dan signifikan secara parsial terhadap kepuasan kerja pada PT. DIKA, serta etos kerja dan job insecurity berpengaruh secara simultan terhadap kepuasan kerja pada PT. DIKA. PT. Danamas Insan Kreasi Andalan (DIKA) Denpasar diharapkan memberikan motivasi kepada karyawannya agar gigih dan tekun dalam bekerja walaupun mengalami kesulitan dan diharapkan memberikan kesempatan untuk promosi bagi karyawan untuk menjadi pegawai tetap kepada karyawan yang telah memenuhi syarat untuk menjadi pegawai tetap. PT. Danamas Insan Kreasi Andalan (DIKA) Denpasar juga diharapkan selalu mengawasi karyawan dalam bekerja agar karyawan mampu menghasilkan pekerjaan sesuai dengan kualitas yang ditentukan. Bagi peneliti selanjutnya, agar dapat meneliti dan mengkaji lebih dalam faktor-faktor lain yang tidak diteliti dalam penelitian ini yang dapat memengaruhi kepuasan kerja selain etos kerja dan job insecurity.

\section{Daftar Pustaka}

Agung, A.A.G. 2011. Pengantar Evaluasi Pendidikan. Singaraja: Universitas Pendidikan Ganesha. -----2014. Metodelogi Penelitian Pendidikan. Yogjakarta: Aditya Media Publishing.

Ardiansyah, Andika. 2017. Pengaruh Gaya Kepemimpinan Dan Etos Kerja Terhadap Kepuasan Kerja Karyawan Pada PT. Taspen (Persero) KC Pematangsiantar. Jurnal Manajemen, Vol 3 No 2

Ciputraceo. 2016. Metode Pengumpulan Data. http://ciputrauceo.net/blog/2016/2/18/metodepengumpulan-data-dalam-penelitian. Diunduh tanggal 30, bulan Oktober, tahun 2019.

Diawati, Mawadha \& Sugesti, Hesty. 2015. Pengaruh Pengembangan Karier Terhadap Kepuasan Kerja Karyawan. Jurnal Diploma 4 Manajemen Bisnis, Vol 1 No 1

Hasthojn. 2012. Job Insecurity. blogspot.com/2012/12/job-insecurity-pada-karyawan-html. Diunduh tanggal 28, bulan Oktober, tahun 2019.

Konsultan statistik. 2009. Uji Asumsi Klasik. http://www.konsultanstatistik.com/2009/03/ujiasumsi-klasik.html. Diunduh tanggal 31, bulan oktober, tahun 2019. 
Kurniawan, Yafet \& Arsanti, Tutuk. 2017. Pengaruh Job Insecurity Terhadap Kepuasan Kerja Dengan Aspek Demografis Sebagai Variabel Moderator. Jurnal Fakultas Ekonomi dan Bisnis, Vol 6 No 2

Sijai. 2019. Teknik Pengumpuan Data. https://sijai.com/teknik-pengumpulan-data/. Diunduh tanggal 30, bulan Oktober, tahun 2019.

Priansa, Donni. 2017. Manajemen Kinerja Kepegawaian. Bandung: Pustaka Setia Bandung

PT. DIKA. 2012. Profil PT.DIKA. https://www.ptdika.com/services Diunduh tanggal 24, bulan Oktober, tahun 2019.

-----2020. Profil PT. DIKA. https://www.ptdika.com/about_us. Diunduh tanggal 1, bulan Juni, tahun 2020

Setiawan, Nyoman \& Putra, Made. 2016. Pengaruh Job Insecurity, Terhadap Kepuasan Kerja Dan Turnover Intention Pada Karyawan legian Village Hotel. Jurnal Jurusan Manajemen, Vol 5 No 8

Setyosari, Punaji. 2015. Metode Penelitian Pendidikan \& Pengembangan. Jakarta: Prenanda Media Group.

Sudaryo, Yoyo., Ariwibowo, Agus., dan Sofiati, Nunung. 2018. Manajemen Sumber Daya Manusia. Yogjakarta: ANDI, CV.

Sugiyono. 2016. Metode Penelitian Pendidikan (Pendekatan Kuantitatif, Kualitatif, R\&D). Bandung: Alfabeta.

-----. 2017. Statistika Untuk Penelitian. Bandung: ALFABETA, cv.

Suparman, Riyanto. 2014. Peningkatan Kepuasan Kerja Melalui Etos Kerja Dan Pembelajaran Organisasi BAPPEDA Kota Banjar. Jurnal Program Studi Manajemen, Vol 5 No 3

Tumbelaka, Steven., Alhabsji, Taher., dan Nimran, Umar. 2016. Pengaruh Budaya Organisasi Terhadap Kepuasan Kerja, Komitmen Organisasional Dan Intention to Leave. Jurnal Magister Ilmu Administrasi Bisnis, Vol 3 No 1

Utami, Intiyas., dan Bonussyeani, Nur. 2009. Pengaruh Pengaruh Job Insecurity, Kepuasan Kerja, dan Komitmen Organisasional Terhadap Keinginan Berpindah Kerja. Jurnal Akutansi dan Keuangan Indonesia, Vol 6 No 1 